ARTICLE

\title{
A photofunctional bottom-up bis(dipyrrinato)zinc(II) complex nanosheet
}

\author{
Ryota Sakamoto ${ }^{1}$, Ken Hoshiko ${ }^{1}$, Qian Liu² ${ }^{2}$ Toshiki Yagi ${ }^{1}$, Tatsuhiro Nagayama ${ }^{1}$, Shinpei Kusaka ${ }^{1}$ \\ Mizuho Tsuchiya', Yasutaka Kitagawa ${ }^{3,4}$, Wai-Yeung Wong ${ }^{2,5}$ \& Hiroshi Nishihara ${ }^{1}$
}

Two-dimensional polymeric nanosheets have recently gained much attention, particularly top-down nanosheets such as graphene and metal chalcogenides originating from bulklayered mother materials. Although molecule-based bottom-up nanosheets manufactured directly from molecular components can exhibit greater structural diversity than top-down nanosheets, the bottom-up nanosheets reported thus far lack useful functionalities. Here we show the design and synthesis of a bottom-up nanosheet featuring a photoactive bis(dipyrrinato)zinc(II) complex motif. A liquid/liquid interfacial synthesis between a threeway dipyrrin ligand and zinc(II) ions results in a multi-layer nanosheet, whereas an air/liquid interfacial reaction produces a single-layer or few-layer nanosheet with domain sizes of $>10 \mu \mathrm{m}$ on one side. The bis(dipyrrinato)zinc(II) metal complex nanosheet is easy to deposit on various substrates using the Langmuir-Schäfer process. The nanosheet deposited on a transparent $\mathrm{SnO}_{2}$ electrode functions as a photoanode in a photoelectric conversion system, and is thus the first photofunctional bottom-up nanosheet.

\footnotetext{
${ }^{1}$ Department of Chemistry, Graduate School of Science, The University of Tokyo, 7-3-1, Hongo, Bunkyo-ku, Tokyo 113-0033, Japan. ${ }^{2}$ Institute of Molecular Functional Materials, Department of Chemistry and Partner State Key Laboratory of Environmental and Biological Analysis, Hong Kong Baptist University, Waterloo Road, Hong Kong, China. ${ }^{3}$ Division of Chemical Engineering, Department of Materials Engineering Science, Graduate School of Engineering Science, Osaka University, 1-3, Machikaneyama, Toyonaka, Osaka 560-8531, Japan. ${ }^{4}$ Department of Chemistry, Graduate School of Science, Osaka University, 1-1, Machikaneyama, Toyonaka, Osaka 560-0043, Japan. ${ }^{5}$ HKBU Institute of Research and Continuing Education, Shenzhen Virtual University Park, Shenzhen 518057, China. Correspondence and requests for materials should be addressed to R.S. (email: sakamoto@chem.s.u-tokyo.ac.jp) or to W.-Y.W. (email: rwywong@hkbu.edu.hk) or to H.N. (email: nisihara@chem.s.u-tokyo.ac.jp).
} 
$\mathrm{N}$ anosheets with two-dimensional polymeric structures have recently attracted significant attention. Graphene, a prominent nanosheet with various attractive properties, has been investigated extensively for applications in electronics $^{1-3}$, photonics ${ }^{4}$ and spintronics ${ }^{5,6}$. The broad attention and expected utility of graphene have stimulated research into other nanosheets, such as metal oxides ${ }^{7-11}$, metal sulfides ${ }^{12-15}$ and metal hydroxides ${ }^{16-20}$, which also exhibit desirable and useful properties (for example, semiconductivity ${ }^{10,15}$ and ferroelectricity $\left.{ }^{8,14}\right)$. These nanosheets originate from bulk-layered crystalline mother materials (that is, top-down nanosheets).

Another type of nanosheets, namely molecule-based bottomup nanosheets, is emerging. This series of nanosheets is fabricated directly from atomic, ionic and molecular components. The concept was proposed nearly a century ago, although it has only recently been realized ${ }^{21}$. For example, Schlüter and King created independently single-layer cycloaddition-induced anthracene ${ }^{22-25}$ nanosheets that featured carbon-carbon

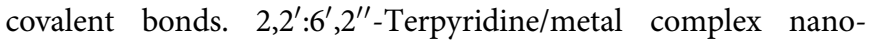
sheets based on a metal-ligand coordination linkage were reported by Schlüter ${ }^{26,27}$. Frauenrath synthesized a carbon-rich nanosheet using carbonization of an amphiphilic hexayne molecule ${ }^{28}$. Other examples include surface metal-organic frameworks ${ }^{29,30}$, surface covalent-organic frameworks $31-34$, metal-surface-mediated monolayer formation in the vacuum phase $^{35-39}$, and single-layer or few-layer metal-organic frameworks and covalent-organic frameworks delaminated from the crystal phase ${ }^{40-46}$. A significant advantage of the bottom-up synthesis is that structures can be customized through the selection of components (for example, metal ions and organic ligand molecules). Therefore, the bottom-up approach may broaden the diversity and utility of nanosheets. Although previous reports on bottom-up nanosheets have concentrated on the fabrication and analysis of various two-dimensional structures, no functionality has yet been demonstrated.
Given this background, we have sought to create functional bottom-up nanosheets, including an electrically conductive nickel bis(dithiolene) nanosheet ${ }^{47-49}$. The present work describes a bis(dipyrrinato)zinc(II) complex nanosheet synthesized from a three-way dipyrrin ligand and zinc(II) acetate. The spontaneous and reversible coordination of dipyrrin ligands with metal ions ${ }^{50,51}$ makes them suitable as building blocks for bottom-up nanosheets. The bis(dipyrrinato)zinc(II) complex motif acts not only as a connecting point but also as a photofunctional moiety: it has a strong absorption in the visible and near-infrared region (tunable by substituents) ${ }^{52-54}$. In addition to the synthesis and identification of the bis(dipyrrinato)zinc(II) complex nanosheet, we report its large domain size (sides of $>10 \mu \mathrm{m}$ ), guest inclusion, stepwise layering and photoelectric conversion ability.

\section{Results}

Synthesis and morphology of multi-layer N1. Figure 1 depicts bis(dipyrrinato)zinc(II) complex nanosheet N1 synthesized from three-way dipyrrin ligand $\mathbf{L} 1$ and zinc(II) acetate. To verify the macroscopic formation of N1, the first process considered was a liquid/liquid interfacial synthesis ${ }^{47}$ using an aqueous zinc(II) acetate solution (upper layer, $5.0 \times 10^{-2} \mathrm{moll}^{-1}$ ) and a dichloromethane solution of $\mathbf{L 1}$ (lower layer, $1.0 \times 10^{-4} \mathrm{moll}^{-1}$; Fig. 2a). A spontaneous reaction at room temperature led to the generation of multilayer N1 at the water/oil interface, which appeared as an orange film. Multi-layer N1 may be transferred from the interface onto various substrates. For example, on an indium tin oxide (ITO) substrate it appears as a transparent film (Fig. 2a). Multi-layer N1 is not soluble in either water or organic solvent, reflecting the polymeric structure proposed in Fig. 1. Optical and scanning electron microscopic images reveal a uniform, flat, film-like morphology (Fig. 2b,c). The presence of cracks and wrinkles also indicates the sheet structure. The typical thickness of multi-layer

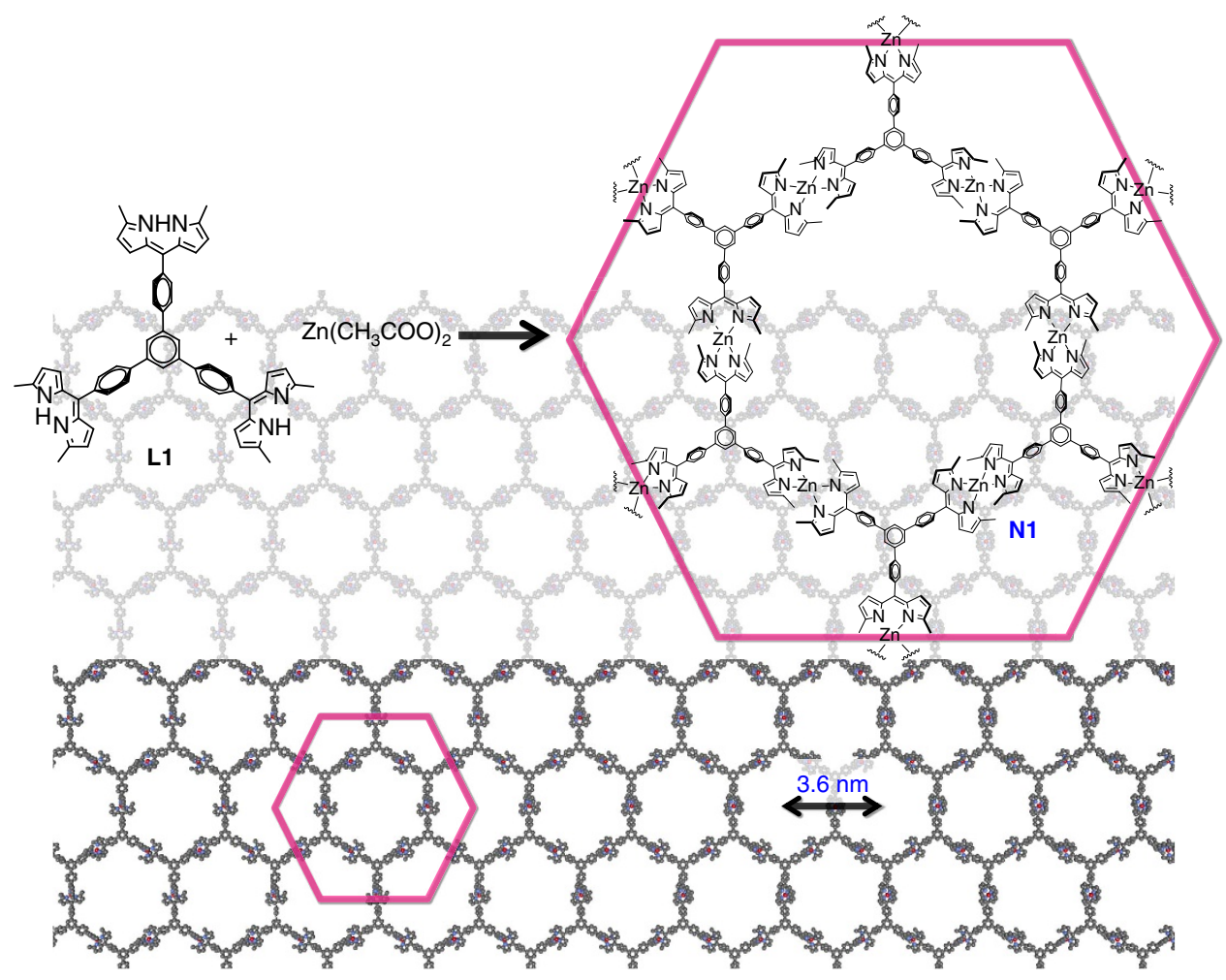

Figure 1 | Bottom-up nanosheet of the present work. Chemical structures of three-way dipyrrin ligand molecule $\mathbf{L 1}$ and bis(dipyrrinato)zinc(II) complex nanosheet $\mathbf{N 1}$. 
a

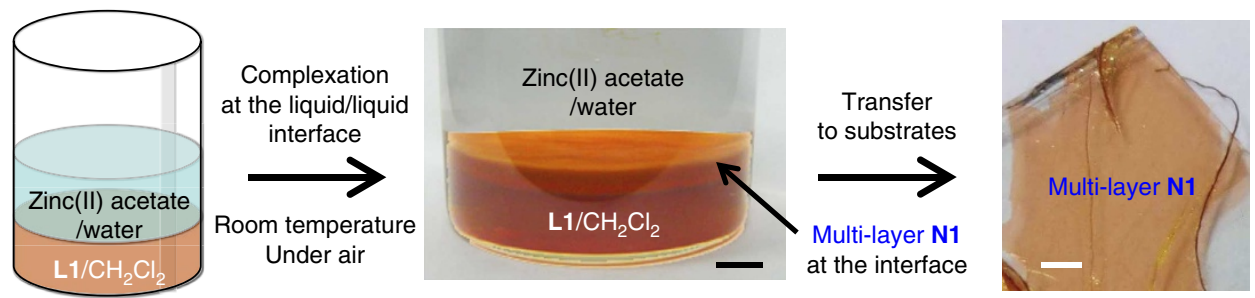

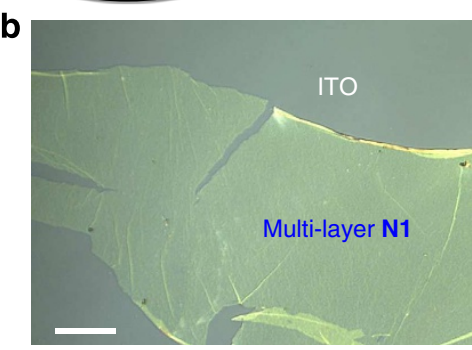

e

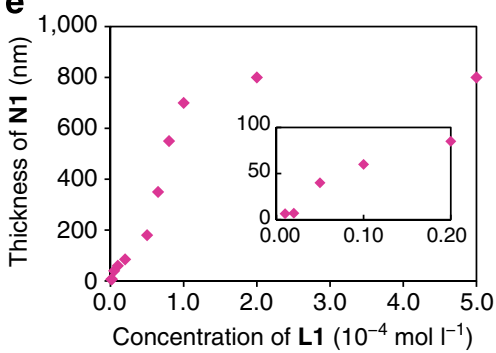

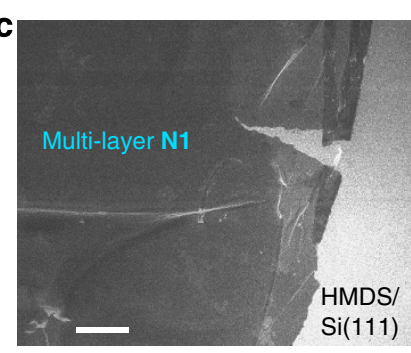

$\mathbf{f}$

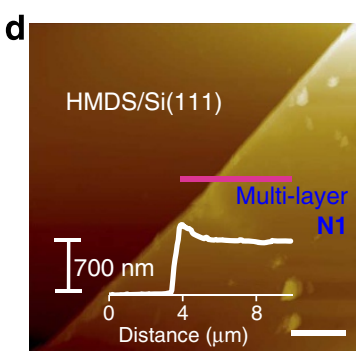

g
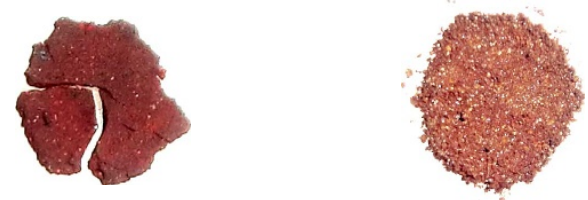

Figure 2 | Synthesis and microscopic analysis of multi-layer N1. (a) Schematic illustration and photographs of the liquid/liquid interfacial synthesis and multi-layer $\mathbf{N} 1$ transferred onto an ITO substrate. Scale bars, 5 and $1 \mathrm{~mm}$, respectively. (b) Optical microscopic image on an ITO substrate. Scale bar, $50 \mu \mathrm{m}$. (c) Field-emission scanning electron microscopic (FE-SEM) image on HMDS/Si(111). Scale bar, $20 \mu \mathrm{m}$. (d) Atomic force microscopic image on HMDS/ $\mathrm{Si}(111)$ and its cross-section analysis along the magenta line. Scale bar, $5 \mu \mathrm{m}$. (e) Control of the thickness based on the concentration of $\mathbf{L} \mathbf{1}$ in the liquid/ liquid interfacial synthesis. The inset shows a close-up of the low concentration region. Reaction time, 4 days. Temperature, room temperature. Container, cylindrical glass vial with a diameter of $3.2 \mathrm{~cm}$. Volume of the upper (aqueous) layer, $20 \mathrm{ml}$. Volume of the lower (dichloromethane) layer, $10 \mathrm{ml}$.

Concentration of zinc(II) acetate in the upper layer, $0.05 \mathrm{moll}^{-1}$. (f,g) Photographs of the products of single-phase reactions in dichloromethane at room temperature and in $\mathrm{N}, \mathrm{N}$-dimethylformamide at $105^{\circ} \mathrm{C}$, respectively.

N1 on a silicon(111) substrate modified with $1,1,1,3,3,3-$ hexamethyldisilazane (HMDS/Si(111)) was observed to be $700 \mathrm{~nm}$ by atomic force microscopy (AFM, Fig. 2d), which corresponds to $\sim 580$ layers considering the thickness of singlelayer N1 (vide infra). The thickness of N1 may be controlled by the concentration of $\mathbf{L 1}$ in dichloromethane and may span 6$800 \mathrm{~nm}$ (5-670 layers) using L1 solutions with concentrations of $1.0 \times 10^{-6}$ to $5.0 \times 10^{-4} \mathrm{moll}^{-1}$ (Fig. $2 \mathrm{e}$ ). We note that the liquid/liquid interfacial synthesis is essential for the synthesis of multi-layer N1. A conventional single-phase synthesis, performed in either dichloromethane at room temperature or $\mathrm{N}, \mathrm{N}$ dimethylformamide at $105^{\circ} \mathrm{C}$, resulted in a solid material far from a film texture (Fig. $2 \mathrm{f}, \mathrm{g}$ ). In fact, its disordered structure was verified by X-ray photoelectron spectroscopy (XPS, vide infra).

Synthesis of single-layer or few-layer N1. Next, we synthesized single-layer N1. Figure 3a shows the fabrication procedure, an air/ liquid interfacial synthesis ${ }^{47-49}$. A very tiny amount $(5 \mu \mathrm{l})$ of a dilute dichloromethane solution of $\mathbf{L 1}\left(7.4 \times 10^{-5} \mathrm{moll}-1\right)$ was gently dropped onto the surface of an aqueous phase containing zinc(II) acetate $\left(5.0 \times 10^{-2} \mathrm{moll}^{-1}\right)$ at ambient temperature. After prompt evaporation of dichloromethane, spontaneous air/ water interfacial complexation occurred between $\mathbf{L} \mathbf{1}$ and zinc(II) ions, and single-layer N1 was produced at the interface. The resultant single-layer $\mathbf{N} 1$ was almost invisible to the naked eye but could be transferred onto various substrates via horizontal

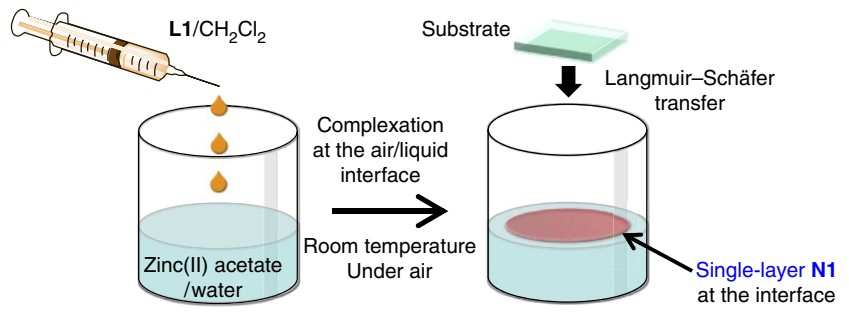

Figure 3 | Synthesis of single-layer N1. Schematic illustration of the air/ liquid interfacial synthesis and transfer process.

deposition known as the Langmuir-Schäfer method (Fig. 3). We note that few-layer N1 was also synthesized by increasing the dichloromethane solution of $\mathbf{L} \mathbf{1}$ to $20 \mu \mathrm{l}$. The single-layer or fewlayer N1 on a flat substrate was then subjected to a series of analyses.

XPS of N1. XPS was conducted for single-layer N1 on HMDS/ $\mathrm{Si}(111)$ to assess its constituent elements ( $\mathrm{N}$ and $\mathrm{Zn}$ ) and their bonding properties (Fig. 4a,b). For reference, dipyrrin ligand L1, mononuclear bis(dipyrrinato)zinc(II) complex M1 (Fig. 4c) and multi-layer N1 deposited on highly ordered pyrolitic graphite (HOPG) were also subjected to XPS. Ligand L1 did not show a $\mathrm{Zn}$ $2 p_{3 / 2}$ peak, whereas the peak was present at similar binding 

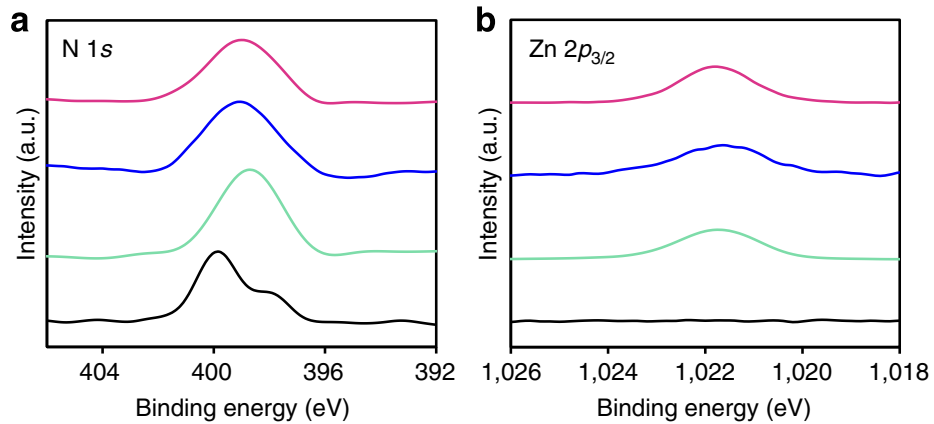

C

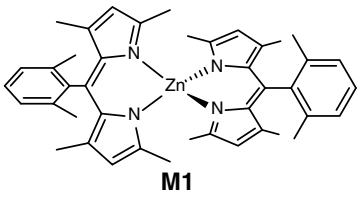

Figure 4 | XPS for N1 and referential compounds. (a) Narrow-scan XPS focusing on the N 1s region. (b) Focusing on the Zn 2p3/2 region. Legend: L1 on HMDS/Si(111) (black), $\mathbf{M 1}$ on adhesive carbon tape (turquoise), multi-layer $\mathbf{N 1}$ on HOPG (blue) and single-layer N1 on HMDS/Si(111) (magenta). The intensity is proportional to the element abundance: the original signal is standardized using the photoionization cross-section of each element. (c) Mononuclear bis(dipyrrinato)zinc(II) reference complex $\mathbf{M 1}$.

energies in the spectra of M1, multi-layer N1 and single-layer N1 (1021.8, 1021.6 and $1021.8 \mathrm{eV}$, respectively). The spectrum of $\mathbf{L 1}$ features two $\mathrm{N} 1 s$ peaks ( 400.0 and $398.4 \mathrm{eV}$ ), assignable to pyrrolic and iminic nitrogen atoms, respectively ${ }^{55}$, whereas M1 shows a single $\mathrm{N} 1 s$ peak at $398.8 \mathrm{eV}$, which originates from its coordination to the zinc(II) centre, which makes the two nitrogen atoms equivalent to one another. Both multi-layer N1 and singlelayer $\mathrm{N} 1$ displayed a single peak for $\mathrm{N} 1 s$ at almost the same binding energy as M1 $(399.0 \mathrm{eV})$. In addition, the abundance ratio calculated from the peak area corrected using the photoionization cross-section is consistent with the ideal value of $\mathrm{N}: \mathrm{Zn}=4: 1$ (80.6:19.4, 80.7:19.3 and 79.1:20.9 for M1, multilayer N1 and single-layer N1, respectively). These findings indicate that the bis(dipyrrinato)zinc(II) complex motif formed quantitatively in the nanosheet. We note that coordination of $\mathrm{H}_{2} \mathrm{O}$ molecule(s) to the zinc(II) centre to form a squarepyramidal or trans-octahedral coordination sphere may be excluded by the fact that multi-layer N1 on oxygen-free HOPG lacked an $\mathrm{O} 1 s$ peak in XPS (Supplementary Fig. 1). Also noteworthy is that the products of the single-phase reactions (Fig. 2f,g) exhibited nitrogen abundancies in excess of the ideal stoichiometric ratio $(\mathrm{N}: \mathrm{Zn}=5.4: 1$ and 5.8:1, Supplementary Fig. 2). This result indicates that the single-phase reaction products leave uncoordinating dipyrrin moieties, thereby possessing disordered structures.

AFM of single-layer or few-layer N1. The AFM analysis revealed the flat sheet texture and morphology of single-layer N1. Figure 5a,b shows the height and phase images, respectively, of single-layer $\mathbf{N} 1$ on an HMDS/Si(111) substrate. The phase image clearly distinguishes single-layer $\mathbf{N} \mathbf{1}$ and the bare substrate: the nanosheet possesses a phase value that is lower by $2.4^{\circ}$. The height image shows a domain with one side $>10-\mu \mathrm{m}$ long, which is a noteworthy size for bottom-up nanosheets ${ }^{29-39}$. To confirm the single-layer nature of the sheet, part of N1 was scratched with the AFM tip at a force of $8.6 \times 10^{2} \mathrm{nN}$. Figure $5 \mathrm{c}$,d shows the height images before and after scratching, and the scratched region is highlighted with a blue square. This treatment resulted in the removal of N1, leaving an intact HMDS/Si(111) surface. A crosssection analysis traversing one of the scratched edges demonstrated that N1 was 1.2-nm thick (Fig. 5e), which is consistent with the size of the bis(dipyrrinato)zinc(II) complex motif. A higher-force scratch $\left(1.2 \times 10^{4} \mathrm{nN}\right)$ resulted in a more drastic change in the AFM image (Supplementary Fig. 3). In this case, both single-layer N1 and the HMDS/Si(111) surface were destroyed.

Few-layer N1 with larger domain sizes was fabricated by increasing the amount of L1 (Supplementary Fig. 4). The phase
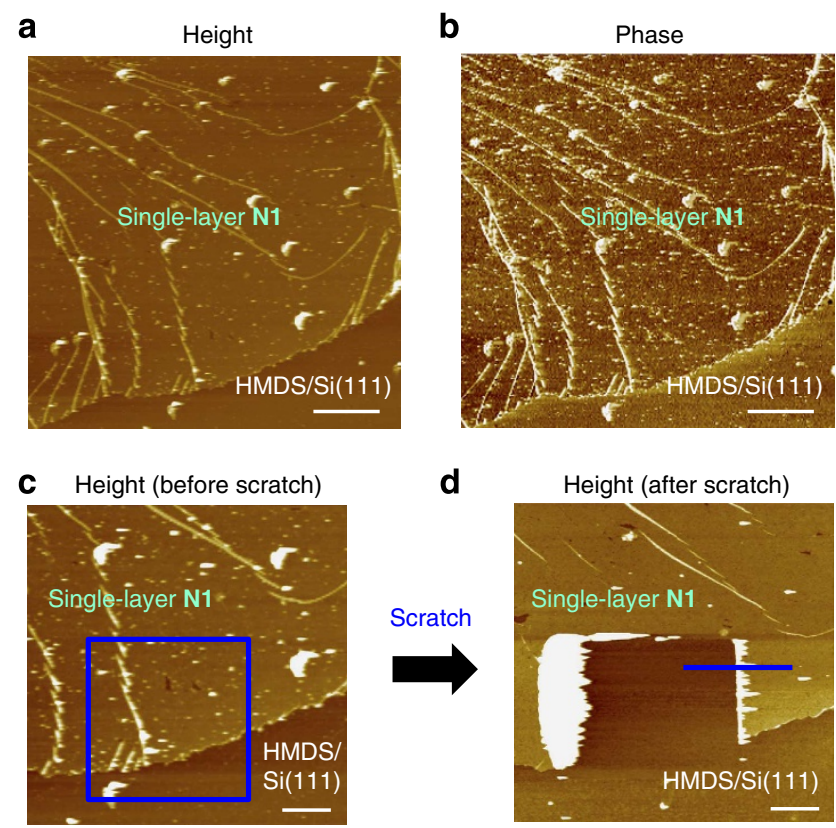

e

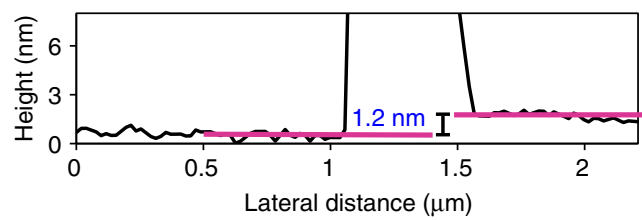

Figure 5 | Atomic force microscopy for single-layer N1. (a,b) Height and phase images on HMDS/Si(111). Scale bar, $2 \mu \mathrm{m}$. (c,d) Height images before and after a scratch by the AFM tip. The blue square indicates the scratched region. Scale bar, $1 \mu \mathrm{m}$. (e) Cross-section analysis at one of the steps in the scratched region (shown as a blue line in $\mathbf{d}$ ).

image is flat, whereas the topological image reveals steps and divided domains. This result indicates that the scanned area was completely covered with few-layer N1. The wrinkles in the layers may be evidence of the sheet structure and were removed by thermal annealing at $120^{\circ} \mathrm{C}$ (Supplementary Fig. 5).

In-plane periodicity. Scanning tunnelling microscopy (STM) revealed that single-layer N1 on HOPG exhibited a moiré pattern composed of two lattices: one is the in-plane hexagonal periodicity of $\mathbf{N 1}$ and the other is derived from HOPG 
(Supplementary Fig. 6). The in-plane periodicity was also confirmed by selected area electron diffractions (SAEDs) in transmission electron microscopy for multi-layer N1 (Supplementary Fig. 7). They represent two sets of hexagonal diffractions, which are consistent with in-plane diffraction patterns reproduced from crystal lattices comprising piles of single-layer N1, which were optimized using a molecular mechanics calculation (Supplementary Fig. 8; Supplementary Information). This series of analyses ensures the hexagonal in-plane periodicity of N1.

Optical properties and layering. Figure 6a presents the ultraviolet/visible spectra of $\mathbf{L} \mathbf{1}$ and $\mathbf{M 1}$ in toluene and of few-layer N1 on a quartz substrate. Ligand $\mathbf{L} \mathbf{1}$ displayed an intense absorption band at $446 \mathrm{~nm}$, which is derived from the ${ }^{1} \pi-\pi^{*}$ transition of the dipyrrin $\pi$-system. Complexation with a zinc(II) ion is known to induce a redshift in the ${ }^{1} \pi-\pi^{\star}$ band $^{53}$, and in fact $\mathbf{M 1}$ displayed a 49-nm wavelength shift relative to L1. Few-layer N1 also showed an absorption band in the visible region, with the absorption maximum being closer to that of M1 than to that of L1, which also indicates that the complexation of $\mathbf{L 1}$ with $\operatorname{zinc}(\mathrm{II})$ ions was complete. Using the ${ }^{1} \pi-\pi^{*}$ band as a probe, single-layer N1 was accumulated stepwise on a quartz substrate. The single-layer nanosheet was fabricated on the air/water interface of a Langmuir-Blodgett trough, which was deposited repeatedly on a quartz substrate at a constant surface pressure using the Langmuir-Schäfer method. Figure $6 \mathrm{~b}$ presents the ultraviolet/ visible spectra of the modified quartz substrate. The peak absorbance of the ${ }^{1} \pi-\pi^{*}$ band at $500 \mathrm{~nm}$ is proportional to the number of deposition processes (Fig. 6c), which indicates the quantitative, layer-by-layer accumulation of single-layer N1.

Guest inclusion. Uptake of a fluorescent dye, Rhodamine B, to N1 with large pores was demonstrated (Supplementary Fig. 9). On immersing multi-layer N1 on an ITO or quartz substrate in a dichloromethane solution of Rhodamine B, N1 was stained the colour of the dye (Supplementary Fig. 9a). Guest-incorporated N1 displayed fluorescence from Rhodamine B (Supplementary Fig. 9b,c).

Photoelectric conversion. N1 was employed as the active layer of a photoanode to demonstrate its functionality. A transparent $\mathrm{SnO}_{2}$ working electrode was decorated with 36-layer N1, and a three-electrode system was set up (Supplementary Fig. 10). Triethanolamine (TEOA) was added to an electrolyte solution as a sacrificial electron donor. An anodic current was observed only when the working electrode was irradiated with 500-nm light, corresponding to the absorption maximum of N1 (Fig. 7a). The action spectrum shown in Fig. $7 \mathrm{~b}$ demonstrates that the photocurrent was maximized with 500-nm light, and no response was observed using light at $\lambda<420 \mathrm{~nm}$ or $\lambda>560 \mathrm{~nm}$, a region of negligible absorption for N1. Control experiments lacking either N1 or TEOA did not show current responses at all (Fig. $7 c, d$ ). Therefore, the observed photocurrent is derived from the photocatalytic oxidation of TEOA sensitized by N1. Surprisingly, to the best of our knowledge, this report is the first on photoelectric conversion using a bis(dipyrrinato)zinc(II) complex sensitizer despite its excellent light absorption ability. We then studied the relationship between the quantum yield of the photoelectric conversion and thickness of N1 (Fig. 7e; Supplementary Fig. 11). Single-layer N1 exhibited the highest value $(0.86 \%)$, which decreases gradually with the growth of the thickness of N1, leading to negligible photoresponses at thicknesses of over $\sim 300$ layers. For the photocurrent, the maximum is located at 100-150 layers (Supplementary Fig. 12). To demonstrate the superiority of N1, we also prepared the two types of mononuclear bis(dipyrrinato)zinc(II) complex sensitizers: plain zinc(II) complex M2, which was dropcasted onto a $\mathrm{SnO}_{2}$ electrode to form a physisorbed film (Supplementary Fig. 13a) and M3 with carboxy groups, which underwent chemisorption onto a $\mathrm{SnO}_{2}$ surface to form a self-assembled monolayer (Supplementary Fig. 14a). These two photoanodes resulted in much lower conversion efficiencies $(0.030$ and $0.069 \%$, Supplementary Figs 13 and 14), thereby justifying the superiority of bottom-up nanosheet N1 over conventional molecular films. The nanosheet structure of $\mathbf{N 1}$ affords appropriate porosity and suppresses molecular aggregation; these features presumably make N1 a better sensitizer. In addition, the coexistence of insolubility (to avoid redissolution into media) and manipulability (to facilitate deposition and layering) of $\mathrm{N1}$ is also advantageous for potential applications.

\section{Discussion}

A photofunctional bottom-up nanosheet containing the photoactive bis(dipyrrinato)zinc(II) complex motif was fabricated. A nanosheet with atomic thickness was prepared via an air/water interfacial synthesis, during which spontaneous complexation proceeded between a three-way dipyrrin ligand and zinc(II) ions at the interface. The nanosheet was identified using ultraviolet/ visible spectroscopy and XPS, which revealed the complete formation of the bis(dipyrrinato)zinc(II) complex motif. The single-layer nanosheet was confirmed by AFM via a scratch experiment. The domain size of the single-layer nanosheet reached $10 \mu \mathrm{m}$ on one side, which is large for bottom-up nanosheet materials. Repeated deposition of the single-layer nanosheet on a flat substrate resulted in its quantitative layering. The nanosheet efficiently collectes visible light at around $500 \mathrm{~nm}$,
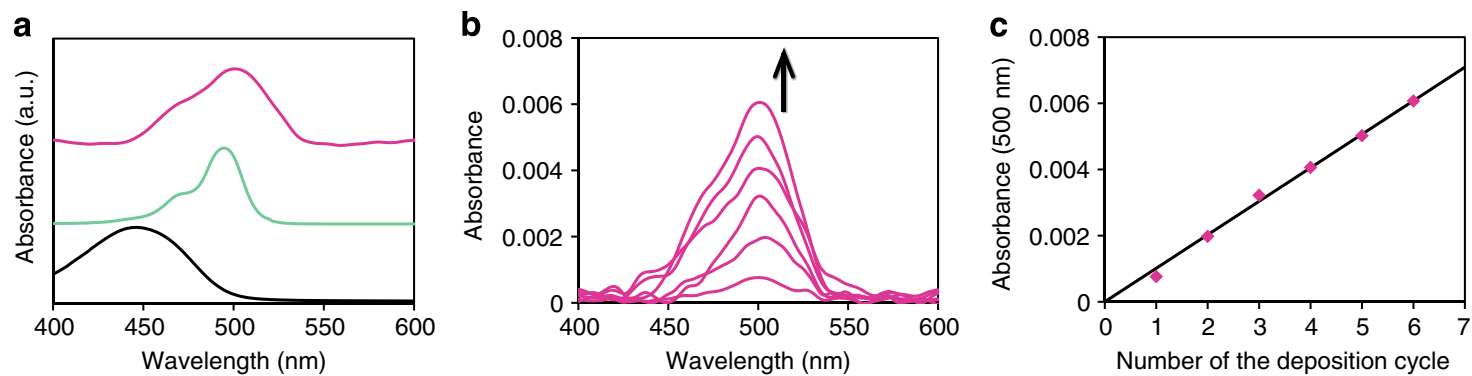

Figure 6 | Ultraviolet/visible spectroscopy. (a) Spectra of L1 (black) and M1 (turquoise) in toluene and few-layer N1 (magenta) on a quartz substrate. (b) Spectral change on stepwise depositions of single-layer $\mathbf{N 1}$ on a quartz substrate. (c) Linear relationship between the absorbance at $500 \mathrm{~nm}$ and the number of deposition processes. The magenta dots are extracted from Fig. 6b, and the black solid line corresponds to the least-squares linear fit of the plots. 
a
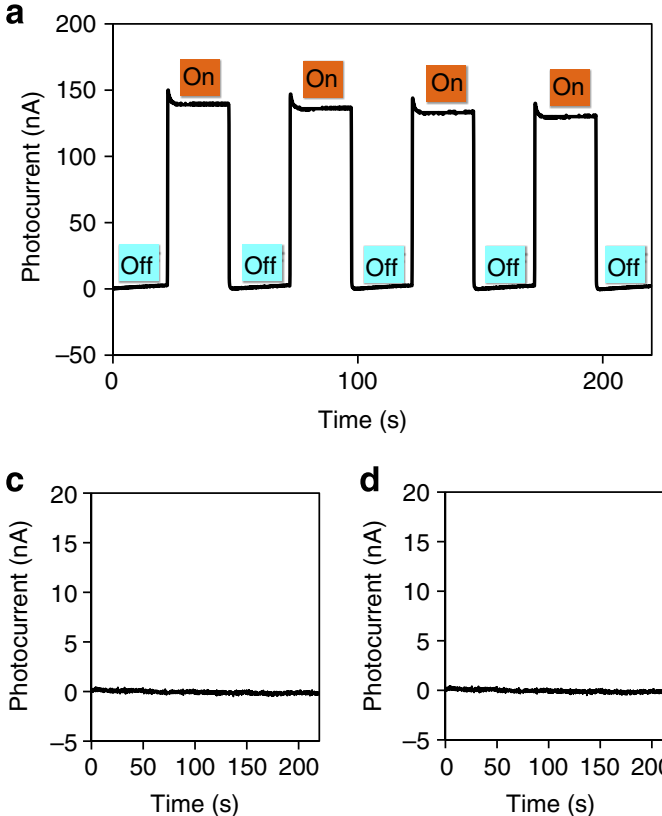

b

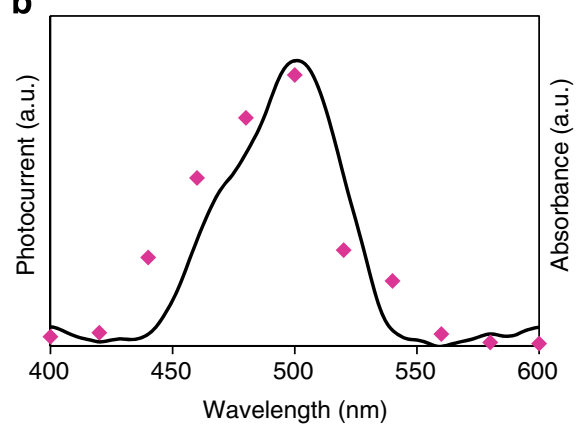

e

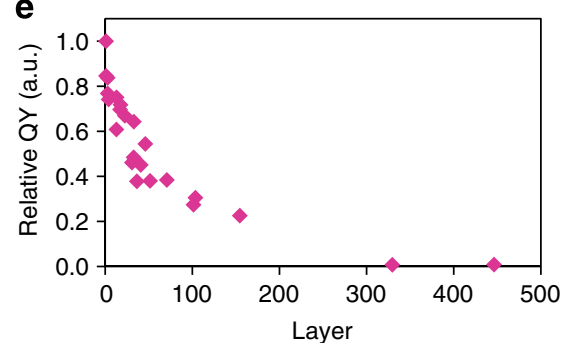

Figure 7 | Photoelectric conversion ability of N1. (a) Typical anodic current response on irradiation of a working electrode $\left(\mathrm{SnO}_{2}\right.$ substrate modified with 36-layer N1) with intermittent 500-nm light. (b) Action spectrum for the photocurrent generation (magenta dots) and absorption spectrum of N1 (black solid line). (c) Control experiment without N1. (d) Control experiment without TEOA. The irradiation pattern is the same as that of a. (e) Relationship between the relative quantum yield (QY) and thickness of $\mathbf{N} 1$ on irradiation with $500-\mathrm{nm}$ light. The highest QY (0.86\% by single-layer N1) is taken as the standard.

and that physisorbed on a transparent $\mathrm{SnO}_{2}$ functioned as an active layer in a photoelectric conversion system. The photofunctionality in the molecule-based bottom-up nanosheet demonstrated herein leads to a significant expansion of the applicability of this type of two-dimensional matters as useful and promising nanomaterials.

\section{Methods}

Materials. $5^{\prime}$-(4-Formylphenyl)- $\left[1,1^{\prime}: 3^{\prime}, 1^{\prime \prime}\right.$-terphenyl $]-4,4^{\prime \prime}$-dicarbaldehyde ${ }^{56}$, 2-methylpyrrole ${ }^{57}, 2$-((3,5-dimethyl-2H-pyrrol-2-ylidene)(2,6-dimethylphenyl) methyl)-3,5-dimethyl-1H-pyrrole ${ }^{54}$ and 2-methyl-5-((5-methyl-2H-pyrrol-2ylidene)(phenyl)methyl)-1H-pyrrole ${ }^{58}$ were synthesized according to previous reports. Dichloromethane, acetonitrile and ethanol for the interfacial synthesis of N1, pretreatments of substrates and photoelectric conversion were supplied from Kanto Chemical Co., Inc. as high-performance liquid chromatography grade and were used as received. Water was purified using a Milli-Q purification system (Merck KGaA). Tetra- $n$-butylammonium perchlorate as a supporting electrolyte was purified by recrystallization from ethanol, which was dried in vacuo. Solvents for organic syntheses were purified using a solvent purification system (Ultimate Solvent System, Nikko Hansen \& Co., Ltd). The other chemicals were general grades and were used as received. All procedures were conducted under an ambient condition otherwise stated.

Apparatus for the identification of molecular compounds. ${ }^{1} \mathrm{H}$ ( 500 or $400 \mathrm{MHz}$ ) and ${ }^{13} \mathrm{C}$ (125 or $100 \mathrm{MHz}$ ) nuclear magnetic resonance (NMR) spectra were recorded on a Bruker-DRX500, JEOL ECX-400 or JEOL AL-400 spectrometer. Fast atom bombardment mass spectrometry (FAB-MS) and electrospray ionization time-of-flight spectrometry were conducted using a JEOL JMS-700 MStation and Micromass LCT Premier XE mass spectrometer, respectively.

Synthesis of L1. $5^{\prime}$-(4-Formylphenyl)-[1, $1^{\prime}: 3^{\prime}, 1^{\prime \prime}$-terphenyl]-4,4' $4^{\prime \prime}$-dicarbaldehyde $(450 \mathrm{mg}, 1.2 \mathrm{mmol})$ and 2 -methylpyrrole $(0.63 \mathrm{ml}, 7.5 \mathrm{mmol})$ were dissolved in dichloromethane $(100 \mathrm{ml})$ under a nitrogen atmosphere. One drop of trifluoroacetic acid was added, and the solution changed from light yellow to bright red and was stirred at room temperature for $3 \mathrm{~h}$. When complete consumption of the aldehyde was confirmed by thin-layer chromatography, a solution of chloranil $(848 \mathrm{mg}, 3.4 \mathrm{mmol})$ in dichloromethane was added, and the resultant mixture was stirred for an additional $15 \mathrm{~min}$. The reaction mixture was washed with water, dried over magnesium sulfate, filtered and evaporated. The crude product was purified by column chromatography on aluminum oxide (activity II-III) with dichloromethane as an eluent to yield a deep-yellow powder (231 mg, 25\%). ${ }^{1} \mathrm{H}$ NMR $\left(400 \mathrm{MHz}, \mathrm{CDCl}_{3}\right): \delta 7.95(\mathrm{~s}, 3 \mathrm{H}), 7.80(\mathrm{~d}, J=8.0 \mathrm{~Hz}, 6 \mathrm{H}), 7.61(\mathrm{~d}, J=8.0$ $\mathrm{Hz}, 6 \mathrm{H}), 6.56(\mathrm{~d}, J=4.0 \mathrm{~Hz}, 6 \mathrm{H}), 6.19(\mathrm{~d}, J=4.0 \mathrm{~Hz}, 6 \mathrm{H}), 2.47(\mathrm{~s}, 18 \mathrm{H}) ;{ }^{13} \mathrm{C} \mathrm{NMR}$ $\left(100 \mathrm{MHz}, \mathrm{CDCl}_{3}\right): \delta 165.18,146.78,141.99,137.88,135.32,132.12,130.51,128.89$, $127.12,116.54,112.11,105.97$ and 18.21; HR-FAB-MS $(\mathrm{m} / \mathrm{z}):[\mathrm{M}]^{+}$calculated for $\mathrm{C}_{57} \mathrm{H}_{48} \mathrm{~N}_{6}, 816.3940$; found, 816.3924.

Synthesis of multi-layer N1. A $50-\mathrm{ml}$ cylindrical glass vial $(3.2 \mathrm{~cm}$ in diameter was used as the reaction container. L1 was dissolved in dichloromethane to a concentration of $1.0 \times 10^{-4} \mathrm{moll}^{-1}$, and $10 \mathrm{ml}$ of the solution was poured into the vial. Then, pure water $(10 \mathrm{ml})$ was layered gently onto the organic phase, which served as a buffer layer. After $2 \mathrm{~h}$, aqueous zinc(II) acetate solution $\left(0.1 \mathrm{moll}^{-1}\right.$, $10 \mathrm{ml}$ ) was slowly added to the buffer layer. The reaction system was left undisturbed for 4 days to obtain an orange film at the liquid/liquid interface. The resulting multi-layer N1 could be deposited on various substrates.

Single-phase reactions between $\mathbf{L 1}$ and zinc(II) acetate. Two types of reaction were performed. Stoichiometric amounts of zinc(II) acetate dihydrate $(4.9 \mathrm{mg}$, $0.022 \mathrm{mmol})$ and $\mathbf{~ L 1}(12.3 \mathrm{mg}, 0.015 \mathrm{mmol})$ were dissolved in dichloromethane $(5 \mathrm{ml})$ in a glass vial. The reaction mixture was allowed to stand at room temperature for 1 day. The resultant product was filtered and washed with dichloromethane, ethanol and water to yield a brown solid (Fig. 2f). In the other type of reaction, stoichiometric amounts of zinc(II) acetate dihydrate $(5.1 \mathrm{mg}, 0.023 \mathrm{mmol})$ and $\mathbf{L} \mathbf{1}(12.2 \mathrm{mg}, 0.015 \mathrm{mmol})$ were dissolved in $N, N$-dimethylformamide $(5 \mathrm{ml})$ in a glass vial. After sealing the vial tightly, the reaction mixture was heated at $105^{\circ} \mathrm{C}$ for 1 day in an oil bath. After being cooled down to room temperature, the resultant product was filtered and washed with dichloromethane, $\mathrm{N}, \mathrm{N}$-dimethylformamide and water to obtain a brown solid (Fig. 2g).

Synthesis of single-layer or few-layer N1. A $50-\mathrm{ml}$ glass vial $(3.2 \mathrm{~cm}$ in diameter $)$ was used as the reaction container. Aqueous zinc(II) acetate $\left(0.05 \mathrm{moll}^{-1}, 30 \mathrm{ml}\right)$ was poured into the vial. A small amount of a dichloromethane solution of $\mathbf{L} \mathbf{1}$ was then sprinkled gently on the surface of the aqueous phase: single-layer N1 was synthesized using $5.0 \mu \mathrm{l}$ of $\mathbf{L 1}$ solution $\left(7.4 \times 10^{-5} \mathrm{moll}^{-1}\right)$, whereas $20 \mu \mathrm{l}$ of $\mathbf{~ L 1}$ solution $\left(7.4 \times 10^{-5} \mathrm{moll}^{-1}\right)$ was used for the few-layer nanosheet. After spontaneous evaporation of the organic solvent, the reaction system was left undisturbed, such that N1 was produced at the air/liquid interface. Single-layer or fewlayer N1 was then transferred onto substrates using the Langmuir-Schäfer method.

Synthesis of mononuclear bis(dipyrrinato)zinc(II) complex M1. Zinc(II) acetate dihydrate $(36.7 \mathrm{mg}, 0.17 \mathrm{~mol})$ and triethylamine $(0.11 \mathrm{ml})$ were added to a 
dichloromethane solution ( $20 \mathrm{ml})$ of 2-((3,5-dimethyl-2H-pyrrol-2-ylidene)(2,6dimethylphenyl)methyl)-3,5-dimethyl- $1 H$-pyrrole $(122 \mathrm{mg}, 0.40 \mathrm{mmol})$, and the reaction mixture was stirred overnight at room temperature. Methanol $(20 \mathrm{ml})$ was added to recrystallize the product as an orange solid $(60.5 \mathrm{mg}, 45 \%) .{ }^{1} \mathrm{H}$ NMR $\left(500 \mathrm{MHz}, \mathrm{CDCl}_{3}\right): \delta 7.21(\mathrm{t}, J=7.6 \mathrm{~Hz}, 2 \mathrm{H}), 7.11(\mathrm{~d}, J=7.6 \mathrm{~Hz}, 4 \mathrm{H}), 5.91(\mathrm{~s}, 4 \mathrm{H})$, $2.16(\mathrm{~s}, 12 \mathrm{H}), 2.04(\mathrm{~s}, 12 \mathrm{H})$ and $1.28(\mathrm{~s}, 12 \mathrm{H}) ;{ }^{13} \mathrm{C}$ NMR $\left(125 \mathrm{MHz}, \mathrm{CDCl}_{3}\right): \delta$ $156.07,143.26,143.06,139.18,135.95,134.27,127.98,127.88,119.74,19.33,16.13$ and 14.70; HR-FAB-MS $(\mathrm{m} / \mathrm{z})$ : $[\mathrm{M}]^{+}$calculated for $\mathrm{C}_{42} \mathrm{H}_{46} \mathrm{~N}_{4} \mathrm{Zn}, 670.3014$; found, 670.3011 .

Synthesis of mononuclear bis(dipyrrinato)zinc(II) complex M2. A solution of 2-methyl-5-((5-methyl-2H-pyrrol-2-ylidene)(phenyl)methyl)- $1 H$-pyrrole (450 mg, $1.8 \mathrm{mmol}$ ) in methanol $(10 \mathrm{ml})$ was poured into a suspension of anhydrous zinc(II) acetate $(168 \mathrm{mg}, 0.92 \mathrm{mmol})$ in methanol $(3 \mathrm{ml})$. The mixture was stirred overnight at room temperature. The reaction mixture was filtered, and the resultant solid was washed with methanol. Filtration yielded a light orange solid (463 mg, 90\%). ${ }^{1} \mathrm{H}$ NMR $\left(400 \mathrm{MHz}, \mathrm{CDCl}_{3}\right): \delta 7.50-7.39(\mathrm{~m}, 10 \mathrm{H}), 6.55(\mathrm{~d}, J=4.0 \mathrm{~Hz}, 2 \mathrm{H}), 6.18(\mathrm{~d}$, $J=4.0 \mathrm{~Hz}, 2 \mathrm{H})$ and $2.12(\mathrm{~s}, 12 \mathrm{H}) ;{ }^{13} \mathrm{C}$ NMR $\left(100 \mathrm{MHz}, \mathrm{CDCl}_{3}\right): \delta 159.44,144.71$, $139.52,139.39,133.22,130.89,128.17,127.14,117.10$ and 16.62; HR-FAB-MS $(\mathrm{m} /$ $z$ ): $[\mathrm{M}]^{+}$calculated for $\mathrm{C}_{42} \mathrm{H}_{46} \mathrm{~N}_{4} \mathrm{Zn}, 558.1762$; found, 558.1782

Synthesis of a precursor for M3. To a dichloromethane $(20 \mathrm{ml})$ solution of ethyl 3-(4-formylphenyl)propanoate $(618 \mathrm{mg}, 3.0 \mathrm{mmol})$ and 2-methylpyrrole $(0.55 \mathrm{ml}$, $6.3 \mathrm{mmol})$, trifluoroacetic acid $(10 \mu \mathrm{l})$ was added, under a nitrogen atmosphere, and the solution was stirred overnight at room temperature. Chloranil $(749 \mathrm{mg}$, $3.0 \mathrm{mmol}$ ) was added and stirred for another $30 \mathrm{~min}$. After evaporation of the solvent, the residue was passed through a short pad of aluminum oxide (activity IIIII) using dichloromethane as an eluent. After evaporation of the solvent, the crude product was purified by column chromatography on aluminum oxide (activity IIIII) with hexane/dichloromethane $(1: 1 \mathrm{v} / \mathrm{v})$ as an eluent. The yellow band was collected and evaporated to yield ethyl 3-(4-((5-methyl-1H-pyrrol-2-yl) (5-methyl$2 \mathrm{H}$-pyrrol-2-ylidene)methyl)phenyl)propanoate as an orange oil (146 mg, 14\%). ${ }^{1} \mathrm{H}$ NMR $\left(500 \mathrm{MHz}, \mathrm{CDCl}_{3}\right) \delta 7.41(\mathrm{~d}, J=8.2 \mathrm{~Hz}, 2 \mathrm{H}), 7.26(\mathrm{~d}, J=8.2 \mathrm{~Hz}, 2 \mathrm{H})$ $6.48(\mathrm{~d}, J=3.8 \mathrm{~Hz}, 2 \mathrm{H}), 6.17(\mathrm{~d}, J=3.8 \mathrm{~Hz}, 2 \mathrm{H}), 4.18(\mathrm{q}, J=7.3 \mathrm{~Hz}, 2 \mathrm{H}), 3.05(\mathrm{t}$, $J=7.9 \mathrm{~Hz}, 2 \mathrm{H}), 2.71(\mathrm{t}, J=7.9 \mathrm{~Hz}, 2 \mathrm{H}), 2.46(\mathrm{~s}, 6 \mathrm{H})$ and $1.28(\mathrm{t}, J=7.3 \mathrm{~Hz}, 3 \mathrm{H})$; ${ }^{13} \mathrm{C}$ NMR $\left(125 \mathrm{MHz}, \mathrm{CDCl}_{3}\right) \delta 172.84,153.67,140.99,139.91,138.30,135.49$, $130.99,128.96,127.41,117.35,60.49,35.81,30.79,16.29$ and 14.27; HR-FAB-MS $(\mathrm{m} / \mathrm{z}):[\mathrm{M}]^{+}$calculated for $\mathrm{C}_{22} \mathrm{H}_{24} \mathrm{~N}_{2} \mathrm{O}_{2}, 348.1829$; found, 348.1838 .

Synthesis of M3. Ethyl 3-(4-((5-methyl-1H-pyrrol-2-yl)(5-methyl-2H-pyrrol-2ylidene)methyl)phenyl)propanoate $(100 \mathrm{mg}, 0.29 \mathrm{mmol})$ was added to tetrahydrofuran $(30 \mathrm{ml})$ and water $(5 \mathrm{ml})$, and the mixture was stirred at room temperature for $5 \mathrm{~min}$. Then, an aqueous solution $(10 \mathrm{ml})$ of $\mathrm{NaOH}(115 \mathrm{mg}$, $2.9 \mathrm{mmol}$ ) was added, and the reaction mixture was stirred overnight at room temperature. After adjusting the $\mathrm{pH}$ of the reaction mixture to 4 using aqueous hydrochloric acid $\left(1.0 \times 10^{-4} \mathrm{moll}^{-1}\right)$, the mixture was poured into water $(50 \mathrm{ml})$ and washed with ether $(20 \mathrm{ml} \times 3)$. The water layer was then treated with a solution of anhydrous zinc(II) acetate $(58 \mathrm{mg}, 0.29 \mathrm{mmol})$ in water $(3 \mathrm{ml})$. The mixture was extracted with dichloromethane and dried over sodium sulfate. The solvent was evaporated under a reduced pressure to yield a dark orange solid of M3 $3.0 \mathrm{mg}$, 3\%). ${ }^{1} \mathrm{H}$ NMR $\left(500 \mathrm{MHz}\right.$, dimethylsulfoxide- $\left.\mathrm{d}_{6}\right): \delta 12.34$ (bs, $\left.2 \mathrm{H}\right), 7.34-7.30(\mathrm{~m}$, $8 \mathrm{H}), 6.33(\mathrm{~d}, J=4.0 \mathrm{~Hz}, 4 \mathrm{H}), 6.20(\mathrm{~d}, J=4.0 \mathrm{~Hz}, 4 \mathrm{H}), 2.91(\mathrm{t}, J=7.6 \mathrm{~Hz}, 4 \mathrm{H}), 2.61$ $(\mathrm{t}, J=7.6 \mathrm{~Hz}, 4 \mathrm{H})$ and $2.39(\mathrm{~s}, 12 \mathrm{H}) ;{ }^{13} \mathrm{C} \mathrm{NMR}\left(125 \mathrm{MHz}, \mathrm{CDCl}_{3}\right) \delta 158.99,144.79$, $139.06,133.29,130.90,130.59,127.60,117.85,31.16,25.62$ and 16.49 (two quaternary carbons are missing because of low solubility or overlaps with other peaks); HR-ESI-MS $(\mathrm{m} / \mathrm{z}):\left[\mathrm{M}-\mathrm{H}^{+}\right]$calculated for $\mathrm{C}_{40} \mathrm{H}_{37} \mathrm{~N}_{4} \mathrm{O}_{4} \mathrm{Zn}, 701.2106$; found, 701.2122 .

Pretreatments for substrates. HOPG was cleaved with a piece of cellophane tape to obtain a flat and clean surface just before use. Si(111) substrates were hydrophobized using HMDS. The procedure to form a HMDS/Si(111) surface is as follows. The $\mathrm{Si}(111)$ substrate covered with a natural $\mathrm{SiO}_{2}$ layer was sonicated in acetone (10 $\mathrm{min})$, 2-propanol $(15 \mathrm{~min} \times 2)$, water $(15 \mathrm{~min})$ and ethanol $(10 \mathrm{~min})$. After rinsing the substrate in ethanol a couple of times, the substrate was immersed in an ethanol solution of HMDS $(1 \mathrm{v} / \mathrm{v} \%)$ for $1 \mathrm{~h}$. The substrate was then washed with ethanol several times before being annealed at $130^{\circ} \mathrm{C}$ for $30 \mathrm{~min}$. The modified substrate was then sonicated in ethanol $(15 \mathrm{~min})$ and water $(10 \mathrm{~min})$ and was stored in water. Just before use, HMDS/Si(111) was sonicated in 2-propanol $(15 \mathrm{~min})$ and water $(15 \mathrm{~min})$, which was dried in vacuo overnight. ITO (on glass), quartz and $\mathrm{SnO}_{2}$ (on ITO-covered glass, $5 \Omega \mathrm{sq}^{-1}$ ) substrates were sonicated in acetone $(10 \mathrm{~min} \times 2)$, water $(10 \mathrm{~min} \times 2)$ and nonionic detergent in water $(30 \mathrm{~min})$. Then, the substrate was washed with water until the bubbles of the detergent disappeared before being sonicated in water $(10 \mathrm{~min} \times 3)$ and ethanol $(10 \mathrm{~min} \times 2)$. The cleaned substrate was stored in water, and dried by nitrogen blow just before use.

Layering of single-layer N1. A Langmuir-Blodgett trough (KSV 2000, KSV NIMA) was used as a reaction container. Before a zinc(II) acetate aqueous solution $\left(0.05 \mathrm{moll}^{-1}\right)$ was poured into the trough as a subphase, the trough was washed with ethanol. The surface of the aqueous solution was cleaned by suctioning the surface of the subphase several times on compressing the trough barrier. Then, a dichloromethane solution of $\mathbf{L} \mathbf{1}\left(7.4 \times 10^{-5} \mathrm{moll}^{-1}, 27.7 \mu \mathrm{l}\right)$ was dropped gently onto the surface of the subphase. Under this condition, the ideal coverage of singlelayer N1 reached $90 \%$ of the trough area. After spontaneous evaporation of the organic solvent, the reaction system was left undisturbed for $4 \mathrm{~h}$, such that singlelayer N1 was produced at the air/liquid interface. The trough was then compressed to yield a trough area of $69.8 \mathrm{~cm}^{2}$ ( $90 \%$ of the initial trough area) at a surface pressure of $0.04 \mathrm{mN} \mathrm{m}^{-1}$. Under these conditions, single-layer $\mathbf{N 1}$ was transferred onto a quartz substrate via the Langmuir-Schäfer method. The trough was then shrunk by the same area as the substrate, and the next transfer was conducted. This process was repeated to layer single-layer N1.

Guest inclusion. Multi-layer N1 (thickness: $700 \mathrm{~nm}$ ) was deposited on a quartz or ITO substrate. The modified substrate was immersed in a dichloromethane solution of Rhodamine $\mathrm{B}\left(5.0 \times 10^{-5} \mathrm{moll}^{-1}\right)$ for $15 \mathrm{~h}$ and was then rinsed with dichloromethane to yield Rhodamine B-encapsulated multi-layer N1.

Analyses for N1. XPS was conducted using a PHI 5,000 VersaProbe (Ulvac-Phi, Inc.). $\mathrm{Al} \mathrm{K \alpha}(15 \mathrm{kV}, 25 \mathrm{~W})$ was used as the X-ray source, and the beam was focused on a $100-\mu \mathrm{m}^{2}$ area. The spectra were analysed with MultiPak Software and standardized using the $\mathrm{C} 1 s$ peak at $284.6 \mathrm{eV}$. AFM and STM were performed using an Agilent Technologies 5,500 scanning probe microscope under an ambient condition. AFM was performed in high-amplitude mode (tapping mode) with a silicon cantilever PPP-NCL (Nano World). The probe for STM (Pt-Ir alloy, 4:1, $0.25 \mathrm{~mm}$ in diameter) was cut from a wire using a nipper to obtain a sharp edge. An optical microscope image was taken using a VHX-100 (Keyence Corporation). A fieldemission scanning electron microscopic image was collected using a JEOL JSM7400FNT. Transmission electron microscopy images/SAED patterns were recorded at accelerating voltage of $75 \mathrm{kV}$ using a Hitachi HF-2000 equipped with an AMTCCD camera. The sample was prepared by depositing multi-layer N1 (thickness: $700 \mathrm{~nm}$ ) on a carbon film supported by a copper grid (ELS-C10, stem Co., Ltd) directly from the liquid/liquid interface. To acquire electron diffractions, we focused on the edge of multi-layer N1. To reproduce the obtained SAED pattern, three-dimensional structures of multi-layer N1, which comprise piles of singlelayer N1, were considered (given as a Supplementary Information and shown in Supplementary Fig. 8). Here we treated AA-, AB- and ABC-stack models, which are often encountered in layered materials ${ }^{59,60}$. The three-dimensional lattice was optimized at the molecular mechanics level of theory with the UFF VALBOND 1.1 force field on an Accelrys Cerius2 ver3.1 program package. The unit cell was assumed to be trigonal such that the $\alpha, \beta$, and $\gamma$ angles were constrained to be $90^{\circ}$, $90^{\circ}$, and $120^{\circ}$, respectively. First, we performed a calculation on the AA-stacking structure with its molecular geometries and cell lengths being fully optimized. Initial structures for the $\mathrm{AB}$ - and $\mathrm{ABC}$-stack models were constructed from the optimized AA-stack one by giving parallel displacement to the B and/or C layers. The SAED patterns were simulated by implementing CrystalMaker 2.6.3 and SingleCrystal 2.3 (CrystalMaker Software Ltd) (Supplementary Fig. 7b-d). Ultraviolet/visible absorption spectra were recorded on a JASCO V-570 spectrometer in transmission mode. A quartz or $\mathrm{SnO}_{2}$ substrate modified with $\mathbf{N 1}$ was set vertical to the probe light. Fluorescence and excitation spectra were recorded on a HITACHI F-4500 fluorospectrometer.

Photoelectric conversion. N1 with thicknesses $\leq 155$ layers was deposited on a transparent $\mathrm{SnO}_{2}$ electrode using the repeated Langmuir-Schäfer procedure shown in Fig. 6b,c. On the other hand, N1 with thicknesses of $>155$ layers was fabricated directly using the liquid/liquid interfacial synthesis (Fig. 2a) and deposited on the electrode. Before photoelectric conversion, each N1 physisorbed on a transparent $\mathrm{SnO}_{2}$ electrode was always subjected to ultraviolet/visible spectroscopy, acquiring spectra from four different positions. This series of measurements allowed us to ensure the uniformity of $\mathbf{N} 1$ and to quantify the thickness of $\mathbf{N} 1$ using the average absorbance at $500 \mathrm{~nm}$ and that of single-layer N1 $(0.00101$ from the slope of Fig. 6c). The average absorbance at $500 \mathrm{~nm}$ was also used in calculating the quantum yield of photoelectric conversion (vide infra). The modified $\mathrm{SnO}_{2}$ electrode was used as a working electrode (photoanode). Silver and platinum wires were employed as reference and counter electrodes, respectively. The resulting three-electrode system was immersed in a homemade photoelectrochemical cell (Supplementary Fig. 10), which was filled with an acetonitrile solution of tetra- $n$ butylammonium perchlorate $\left(0.1 \mathrm{moll}^{-1}\right)$ containing TEOA $\left(0.05 \mathrm{moll}^{-1}\right)$ as a sacrificial donor reagent. The cell was sealed and deoxygenized by argon bubbling for $30 \mathrm{~min}$. Monochromatic light for the action spectrum shown in Fig. $7 \mathrm{~b}$ $(400-600 \mathrm{~nm}$ in every $20 \mathrm{~nm}$ ) was extracted from a xenon lamp (MAX-302, Asahi Spectra Co., Ltd), the photon flux of which was monochromated by a monochromator (CT-10, JASCO Corporation). For the other experiments, 500-nm light was used exclusively, which was provided by the xenon lamp equipped with a band-pass filter. The active area of the electrode was $0.264 \mathrm{~cm}^{2}$, which was determined by a fluorocarbon rubber o-ring (Supplementary Fig. 10). The electrode potential and photocurrent acquisition of the photoelectric conversion system were controlled using an electrochemical analyser (ALS 750A, BAS Inc.). 
The photoanode was fixed at $0.0 \mathrm{~V}$ versus the silver reference electrode for the data shown in Fig. $7 \mathrm{a}-\mathrm{d}$ and $0.15 \mathrm{~V}$ for the other data, including those for M2 and M3. At both potentials, no anodic current induced by the direct oxidation of TEOA in the dark was observed. The quantum yield of photoelectric conversion, $\phi$, was calculated using equation (1):

$$
\phi=n_{\mathrm{e}} / n_{\mathrm{p}},
$$

where $n_{\mathrm{e}}$ is the mole of electrons that flows in the circuit per unit time (in mol s${ }^{-1}$ ) and $n_{\mathrm{p}}$ is the mole of photons absorbed by the sensitizer per unit time (in $\mathrm{mol} \mathrm{s}^{-1}$ ). $n_{\mathrm{e}}$ and $n_{\mathrm{p}}$ were calculated using equations (2) and (3):

$$
\begin{gathered}
n_{\mathrm{e}}=i / F \\
n_{\mathrm{p}}=W \lambda\left[1-10^{-A}\right] / N_{\mathrm{A}} h c,
\end{gathered}
$$

where $i$ is the current flow (in A), $F$ is the Faraday constant $\left(9.65 \times 10^{4} \mathrm{C} \mathrm{mol}^{-1}\right)$, $W$ is the photon flux of incident light (in $\mathrm{J} \mathrm{s}^{-1}$ ), $\lambda$ is the wavelength of the irradiated light $\left(5.00 \times 10^{-7} \mathrm{~m}\right), A$ is the absorbance at the irradiated wavelength, $N_{\mathrm{A}}$ is the Avogadro constant $\left(6.02 \times 10^{23} \mathrm{~mol}^{-1}\right), h$ is the Planck constant $\left(6.63 \times 10^{-34} \mathrm{Js}\right)$ and $c$ is the velocity of light $\left(3.00 \times 10^{8} \mathrm{~m} \mathrm{~s}^{-1}\right)$. A representative data set for the determination of $\phi$ for $\mathbf{N} 1$ is shown in Supplementary Fig. 11. $i$ was calculated using equation (4):

$$
i=i_{\mathrm{L}}-i_{\mathrm{D}},
$$

where $i_{\mathrm{L}}$ is the average light current for the first cycle $(10 \mathrm{~s})$ and $i_{\mathrm{D}}$ is the average dark current just before the illumination of light. A photon counter $(8230 \mathrm{E}$ and 82311B, ADC Corporation) was employed for the quantification of $W$. For every sample, $W$ was measured independently. A typical value for $W$ was $\sim 0.20 \mathrm{~mW}$. When $i$ was below the measurable level $(<1.0 \mathrm{nA}), W$ was increased to $1.0-2.0 \mathrm{~mW}$ such that the photocurrent signal was amplified. For referential mononuclear complex M2, film formation was conducted as follows: two droplets from a disposable Pasteur pipette of an acetonitrile solution of M2 $\left(1.86 \times 10^{-5} \mathrm{moll}^{-1}\right)$ were dripped onto a $\mathrm{SnO}_{2}$ substrate $\left(\sim 0.8 \mathrm{~cm}^{2}\right)$. The substrate was then dried under vacuum for $10 \mathrm{~min}$ to allow the solvent to evaporate. The modified $\mathrm{SnO}_{2}$ electrode was subjected to photoelectric conversion, following the procedure for $\mathbf{N} 1$ except that aqueous $0.1 \mathrm{moll}^{-1}$ sodium sulfate was used as an electrolyte solution; this change prevented the M2 film from redissolution. Referential mononuclear complex M3 was immobilized on a $\mathrm{SnO}_{2}$ electrode through the carboxy group using the self-assembled monolayer procedure ${ }^{61}$. $\mathrm{A} \mathrm{SnO}_{2}$ substrate was immersed in a dimethylsulfoxide solution of $\mathbf{M} 3\left(1.96 \times 10^{-3} \mathrm{moll}^{-1}\right)$ for 1 day at room temperature, and the decorated substrate was rinsed with dimethylsulfoxide and dried by an argon blow. The modified $\mathrm{SnO}_{2}$ electrode was subjected to photoelectric conversion using the same procedure as N1.

\section{References}

1. Novoselov, K. S. et al. Electric field effect in atomically thin carbon films. Science 306, 666-669 (2004).

2. Geim, A. K. \& Novoselov, K. S. The rise of graphene. Nat. Mater. 6, 183-191 (2007).

3. Lin, Y.-M. et al. $100-\mathrm{GHz}$ transistors from wafer-scale epitaxial graphene. Science 327, 662 (2010).

4. Bonaccorso, F., Sun, Z., Hasan, T. \& Ferrari, A. C. Graphene photonics and optoelectronics. Nat. Photonics 4, 611-622 (2010).

5. Son, Y.-W., Cohen, M. L. \& Louie, S. G. Half-metallic graphene nanoribbons. Nature 444, 347-349 (2006).

6. Maassen, J., Ji, W. \& Guo, H. Graphene spintronics: the role of ferromagnetic electrodes. Nano Lett. 11, 151-155 (2011).

7. Sasaki, T., Watanabe, M., Hashizume, H., Yamada, H. \& Nakazawa, H. Macromolecule-like aspects for a colloidal suspension of an exfoliated titanate. Pairwise association of nanosheets and dynamic reassembling process initiated from it. J. Am. Chem. Soc. 118, 8329-8335 (1996).

8. Li, B.-W. et al. Engineered interfaces of artificial perovskite oxide superlattices via nanosheet deposition process. ACS Nano 4, 6673-6680 (2010).

9. Umar, A. \& Hahn, Y. B. ZnO nanosheet networks and hexagonal nanodiscs grown on silicon substrate: growth mechanism and structural and optical properties. Nanotechnology 17, 2174-2180 (2006).

10. Sakai, N., Ebina, Y., Takada, K. \& Sasaki, T. Electronic band structure of titania semiconductor nanosheets revealed by electrochemical and photoelectrochemical studies. J. Am. Chem. Soc. 126, 5851-5858 (2004).

11. Muramatu, M. et al. Fabrication of densely packed titania nanosheet films on solid surface by use of Langmuir-Blodgett deposition method without amphiphilic additives. Langmuir 21, 6590-6595 (2005).

12. Coleman, J. N. et al. Two-dimensional nanosheets produced by liquid exfoliation of layered materials. Science 331, 568-571 (2011).

13. Splendiani, A. et al. Emerging photoluminescence in monolayer $\mathrm{MoS}_{2}$. Nano Lett. 10, 1271-1275 (2010).

14. Lee, H. S. et al. $\mathrm{MoS}_{2}$ nanosheets for top-gate nonvolatile memory transistor channel. Small 8, 3111-3115 (2012).

15. Zeng, Z. et al. Single-layer semiconducting nanosheets: high-yield preparation and device fabrication. Angew. Chem. Int. Ed. 50, 11093-11097 (2011).
16. Ma, R., Liu, Z., Li, L., Iyi, N. \& Sasaki, T. Exfoliating layered double hydroxides in formamide: a method to obtain positively charged nanosheets. J. Mater. Chem. 16, 3809-3813 (2006).

17. Ma, R. et al. Synthesis and exfoliation of $\mathrm{Co}^{2+}-\mathrm{Fe}^{3+}$ layered double hydroxides: an innovative topochemical approach. J. Am. Chem. Soc. 129, 5257-5263 (2007).

18. Ida, S., Shiga, D., Koinuma, M. \& Matsumoto, Y. Synthesis of hexagonal nickel hydroxide nanosheets by exfoliation of layered nickel hydroxide intercalated with dodecyl sulfate ions. J. Am. Chem. Soc. 130, 14038-14039 (2008).

19. Yan, D. et al. Ordered poly( $p$-phenylene)/layered double hydroxide ultrathin films with blue luminescence by layer-by-layer assembly. Angew. Chem. Int. Ed. 48, 3073-3076 (2009).

20. Yan, D. et al. Reversibly thermochromic, fluorescent ultrathin films with a supramolecular architecture. Angew. Chem. Int. Ed. 50, 720-723 (2011).

21. Sakamoto, J., van Heijst, J., Lukin, O. \& Schlüter, A. D. Two-dimensional polymers: just a dream of synthetic chemists? Angew. Chem. Int. Ed. 48, 1030-1069 (2009).

22. Kissel, P. et al. A two-dimensional polymer prepared by organic synthesis. Nat. Chem 4, 287-291 (2012).

23. Payamyar, P. et al. Synthesis of a covalent monolayer sheet by photochemical anthracene dimerization at the air/water interface and its mechanical characterization by AFM indentation. Adv. Mater. 26, 2052-2058 (2014).

24. Kory, M. J. et al. Gram-scale synthesis of two-dimensional polymer crystals and their structure analysis by X-ray diffraction. Nat. Chem. 6, 779-784 (2014).

25. Kissel, P., Murray, D. J., Wulftange, W. J., Catalano, V. J. \& King, B. T. A nanoporous two-dimensional polymer by single-crystal-to-single-crystal photopolymerization. Nat. Chem. 6, 774-778 (2014).

26. Bauer, T. et al. Synthesis of free standing, monolayered organometallic sheets at the air/water interface. Angew. Chem. Int. Ed. 50, 7879-7884 (2011).

27. Zheng, Z. et al. Synthesis of two-dimensional analogues of copolymers by siteto-site transmetalation of organometallic monolayer sheets. J. Am. Chem. Soc 136, 6103-6110 (2014).

28. Schrettl, S. et al. Functional carbon nanosheets prepared from hexayne amphiphile monolayers at room temperature. Nat. Chem. 6, 468-476 (2014).

29. Makiura, R. et al. Surface nano-architecture of a metal-organic framework. Nat. Mater. 9, 565-571 (2010).

30. Motoyama, S., Makiura, R., Sakata, O. \& Kitagawa, H. Highly crystalline nanofilm by layering of porphyrin metal-organic framework sheets. J. Am. Chem. Soc. 133, 5640-5643 (2011).

31. Zwaneveld, N. A. A. et al. Organized formation of 2D extended covalent organic frameworks at surfaces. J. Am. Chem. Soc. 130, 6678-6679 (2008).

32. Tanoue, R. et al. Thermodynamically controlled self-assembly of covalent nanoarchitectures in aqueous solution. ACS Nano 5, 3923-3929 (2011).

33. Dienstmaier, J. F. et al. Synthesis of well-ordered COF monolayers: surface growth of nanocrystalline precursors versus direct on-surface polycondensation. ACS Nano 5, 9737-9745 (2011).

34. Liu, X.-H. et al. On-surface synthesis of single-layered two-dimensional covalent organic frameworks via solid-vapor interface reactions. J. Am. Chem. Soc. 135, 10470-10474 (2013).

35. Grill, L. et al. Nano-architectures by covalent assembly of molecular building blocks. Nat. Nanotech. 2, 687-691 (2007).

36. Gutzler, R. et al. Surface mediated synthesis of $2 \mathrm{D}$ covalent organic frameworks 1,3,5-tris(4-bromophenyl)benzene on graphite(001), $\mathrm{Cu}(111)$, and $\mathrm{Ag}(110)$. Chem. Commun. 4456-4458 (2009).

37. Abel, M., Clair, S., Ourdjini, O., Mossayan, M. \& Porte, L. Single-layer of polymeric Fe-phthalocyanine: an organometallic sheet on metal and thin insulating film. J. Am. Chem. Soc. 133, 1203-1205 (2011).

38. Li, Y. et al. Coordination and metalation bifunctionality of $\mathrm{Cu}$ with 5,10,15,20tetra(4-pyridyl)porphyrin: toward a mixed-valence two-dimensional coordination network. J. Am. Chem. Soc. 134, 6401-6408 (2012).

39. Sirtl, T. et al. Control of intermolecular bonds by deposition rates at room temperature: hydrogen bonds versus metal coordination in trinitrile monolayers. J. Am. Chem. Soc. 135, 691-695 (2013).

40. Berlanga, I. et al. Delamination of layered covalent organic frameworks. Small 7, 1207-1211 (2011).

41. Berlanga, I., Rubén, M.-B. \& Zamora, F. Tuning delamination of layered covalent organic frameworks through structural design. Chem. Commun. 48, 7976-7978 (2012).

42. Bunck, D. N. \& Dichtel, W. R. Bulk synthesis of exfoliated two-dimensional polymers using hydrazone-linked covalent organic frameworks. J. Am. Chem. Soc. 135, 14952-14955 (2013).

43. Amo-Ochoa, P. et al. Single layers of a multifunctional laminar $\mathrm{Cu}(\mathrm{I}, \mathrm{II})$ coordination polymer. Chem. Commun. 46, 3262-3264 (2010).

44. Li, P.-Z., Maeda, Y. \& Xu, Q. Top-down fabrication of crystalline metal-organic framework nanosheet. Chem. Commun. 47, 8436-8438 (2011).

45. Tan, J.-C., Saines, P. J., Bithell, E. G. \& Cheetham, A. K. Hybrid nanosheets of an inorganic-organic framework material: facile synthesis, structure, and elastic properties. ACS Nano 6, 615-621 (2012). 
46. Xu, G., Yamada, T., Otsubo, K., Sakaida, S. \& Kitagawa, H. Facile 'modular assembly' for fast construction of a highly oriented crystalline MOF nanofilm. J. Am. Chem. Soc. 134, 16524-16527 (2012).

47. Kambe, T. et al. $\pi$-conjugated nickel bisdithiolene complex nanosheet. J. Am. Chem. Soc. 135, 2462-2465 (2013).

48. Hoshiko, K., Kambe, T., Sakamoto, R., Takada, K. \& Nishihara, H. Fabrication of dense and multi-layered films of the nickel bis(dithiolene) nanosheet by means of the Langmuir-Schäfer method. Chem. Lett. 43, 252-253 (2014).

49. Kambe, T. et al. Redox control and high conductivity of nickel bis(dithiolene) complex $\pi$-nanosheet: A potential organic two-dimensional topological insulator. J. Am. Chem. Soc. 136, 14357-14360 (2014).

50. Wood, T. E. \& Thompson, A. Advances in the chemistry of dipyrrins and their complexes. Chem. Rev. 107, 1831-1861 (2007).

51. Maeda, H. et al. Nanoscale spherical architectures fabricated by metal coordination of multiple dipyrrin moieties. J. Am. Chem. Soc. 128 , 10024-10025 (2006)

52. Sazanovich, I. V. et al. Structural control of the excited-state dynamics of bis(dipyrrinato)zinc complexes: self-assembling chromophores for lightharvesting architectures. J. Am. Chem. Soc. 126, 2664-2665 (2004).

53. Kusaka, S., Sakamoto, R., Kitagawa, Y., Okumura, M. \& Nishihara, H. An extremely bright heteroleptic bis(dipyrrinato)zinc(II) complex. Chem. Asian J. 7, 907-910 (2012).

54. Tsuchiya, M. et al. Asymmetric dinuclear bis(dipyrrinato)zinc(II) complexes: Broad absorption and unidirectional quantitative exciton transmission. Chem. Commun. 50, 5881-5883 (2014).

55. Karweik, D. H. \& Winograd, N. Nitrogen charge distributions in free-base porphyrins, metalloporphyrins, and their reduced analogs observed by X-ray photoelectron spectroscopy. Inorg. Chem. 15, 2336-2342 (1976).

56. Wang, Z. et al. Phenanthro[9,10- $d$ ]imidazole as a new building block for blue light emitting materials. J. Mater. Chem. 21, 5451-5456 (2011).

57. Micheal, M.-C. L. \& Gregory, C. F. Cu(I)/bis(azaferrocene)-catalyzed enantioselective synthesis of $\beta$-lactams via couplings of alkynes with nitrones. J. Am. Chem. Soc. 124, 4572-4573 (2002)

58. Qin, W., Baruah, M., Van der Auweraer, M., De Schryver, F. C. \& Boens, N. Photophysical properties of borondipyrromethene analogues in solution. J. Phys. Chem. A 109, 7371-7384 (2005).

59. Spitler, E. L. \& Dichtel, W. R. Lewis acid-catalysed formation of twodimensional phthalocyanine covalent organic frameworks. Nat. Chem. 2, 672-677 (2010)

60. Ping, J. \& Fuhrer, M. S. Layer number and stacking sequence imaging of fewlayer graphene by transmission electron microscopy. Nano Lett. 12, 4635-4641 (2012).

61. Nagaoka, S., Horiuchi, K., Shikishima, M. \& Nakajima, A. Physical properties of aliphatic monolayer on indium-tin oxide and $\mathrm{SnO}_{2}(110)$ relevant to thermal stability of soft-landed Cr(benzene) ${ }_{2}$. J. Phys. Chem. C 115, 24215-24220 (2011).

\section{Acknowledgements}

We acknowledge Grants-in-Aid from MEXT of Japan (Nos. 24750054, 25107510, 26708005, 26107510, 26620039, 21108002, 26220801, 26248017, 26110505, 26410093, areas 2107 (Coordination Programming), 2406 (All Nippon Artificial Photosynthesis Project for Living Earth), 2506 (Science of Atomic Layers), and 2509 (Molecular
Architectonics)). R.S. is grateful to Ogasawara Foundation for the Promotion of Science and Engineering, Noguchi Institute, Tokuyama Science Foundation, Asahi Glass Foundation, The Murata Science Foundation, Iketani Science and Technology Foundation, The Japan Prize Foundation, Kao Foundation for Arts and Sciences, Japan Association for Chemical Innovation, The MIKIYA Science and Technology Foundation, Yazaki Memorial Foundation for Science and Technology, Shorai Foundation for Science and Technology, The Kurata Memorial Hitachi Science and Technology Foundation, Kumagai Foundation for Science and Technology, and The Japan Science Society for financial supports. W.-Y.W. thanks the Hong Kong Research Grants Council (HKBU 12302114), Areas of Excellence Scheme of HKSAR (AoE/P-03/08), National Natural Science Foundation of China (Project Nos. 51373145 and 91333206), Science, Technology, and Innovation Committee of Shenzhen Municipality (JCYJ20140419130507116) and Hong Kong Baptist University (FRG2/13-14/083) for the financial support. This work was also supported by the Partner State Key Laboratory of Environmental and Biological Analysis (SKLP-14-15-P011) and Strategic Development Fund of HKBU. K.H acknowledges Fostering program of human resources in chemistry conducted by Japan Chemical Industry Association. M.T. is grateful to Advanced Leading Graduate Course for Photon Science (ALPS) and the JSPS fellowship for young scientists. Y.K. expresses gratitude to Professor Mitsutaka Okumura for valuable supports and discussion on the molecular mechanics calculation. We also thank the Research Hub Advanced Nano Characterization (The University of Tokyo) and Dr Tetsuro Kusamoto (The University of Tokyo) for XPS and electrospray ionization time-of-flight spectrometry measurements, respectively.

\section{Author contributions}

R.S. conceived and directed the project. R.S., H.N., K.H. and W.-Y.W. initiated the project. S.K., Q.L. and W.-Y.W. synthesized ligand L1. K.H., Q.L. and T.N. performed the fabrication of N1 and M1. T.N. and M.T. synthesized M2 and M3, respectively. Y.K. optimized the three-dimensional lattice of multi-layer $\mathbf{N 1}$ at the molecular mechanics level of theory. K.H. conducted the characterization of N1. T.Y. and K.H. investigated the photoelectric conversion of N1, M2 and M3. R.S. and K.H. co-wrote the manuscript.

\section{Additional information}

Supplementary Information accompanies this paper at http://www.nature.com/ naturecommunications.

Competing financial interests: The authors declare no competing financial interests.

Reprints and permission information is available online at http://npg.nature.com/ reprintsandpermissions.

How to cite this article: Sakamoto, R. et al. A photofunctional bottom-up bis(dipyrrinato)zinc(II) complex nanosheet. Nat. Commun. 6:6713 doi: 10.1038/ncomms7713 (2015).

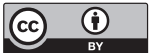

This work is licensed under a Creative Commons Attribution 4.0 International License. The images or other third party material in this article are included in the article's Creative Commons license, unless indicated otherwise in the credit line; if the material is not included under the Creative Commons license, users will need to obtain permission from the license holder to reproduce the material. To view a copy of this license, visit http://creativecommons.org/licenses/by/4.0/ 